\title{
Assessment of relative position of infraorbital foramen in dry adult skulls and its clinical implication
}

\author{
(1) Varalakshmi KL로 , (1) Jyothi N. Nayak ${ }^{2}$ \\ ${ }_{1}$ MVJ Medical College and Research Hospital, Clinic of Anatomy, Bangalore, India \\ 2DAPM RV Dental College, Clinic of Anatomy, Bangalore, India
}

\section{Date submitted:}

16.07.2020

Date accepted:

23.11.2020

Online publication date: 15.09.2021

\section{Corresponding Author:}

Varalakshmi KL, M.D., MVJ Medical

College and Research Hospital, Clinic

of Anatomy, Bangalore, India

drvara.hitesh@gmail.com

\section{ORCID:}

orcid.org/0000-0002-6792-2240

Keywords: Infraorbital foramen, zygomatico-maxillary suture, anterior nasal spine, Le Fort type-1 osteotomy, accessory foramen

\begin{abstract}
Aims: Knowledge of the location of infraorbital foramen (IOF) is important to avoid injuries to neurovascular structure which passes through it, as it may occur in surgical procedures such as rhinoplasty, Caldwell-Luc surgical procedures, tumor surgery, orbita basis reduction, malar region fractures, and Le Fort type-1 osteotomy. Hence, this foramen should be approached carefully to avoid damage.

Methods: Ninety dried skull bones of unknown sex, obtained from the clinic of anatomy, MVJ Medical College and Research Hospital, were used to study the shape, size, relation to maxillary tooth, presence of accessory foramen and distance of IOF from surface landmarks and results were analyzed statistically.
\end{abstract}

Results: The vertical and horizontal diameters of IOF were $3.29 \pm 0.82 \mathrm{~mm}$ and $3.77 \pm 0.85 \mathrm{~mm}$ on the right side, and $3.37 \pm 0.81 \mathrm{~mm}$ and $3.90 \pm 0.96 \mathrm{~mm}$ on the left side, respectively. Oval shape was more common. The distance between IOF and infraorbital margin was $6.34 \pm 1.63 \mathrm{~mm}$ on the right side and $6.40 \pm 1.48 \mathrm{~mm}$ on the left side; alveolar margin of maxilla was $27.82 \pm 4.13$ $\mathrm{mm}$ on the right and was $28.40 \pm 3.40 \mathrm{~mm}$ on the left side; zygomatico-maxillary suture was $14.11 \pm 2.23$ on the right side and $13.87 \pm 3.59 \mathrm{~mm}$ on the left side; and anterior nasal spine was $32.21 \pm 3.07 \mathrm{~mm}$ on the right side and $32.26 \pm 2.29 \mathrm{~mm}$ on the left side. Accessory foramen was seen in $7(7.7 \%)$ skulls. The location of foramen was along $1^{\text {st }}$ premolar tooth on the right side and towards the $2^{\text {nd }}$ premolar tooth on the left side.

Conclusions: This study makes it possible to identify the exact position of IOF and its application in various surgical procedures.

\section{Introduction}

Infraorbital foramen (IOF) is an opening located on the anterior surface of maxilla, about $1 \mathrm{~cm}$ below the infraorbital margin. It transmits infraorbital nerve and infraorbital vessels. The infraorbital nerve is a continuation of maxillary nerve which runs along the floor of orbit in the infraorbital groove and canal, and appears in the face through the IOF below the origin of levator labii superioris muscle (1). The infraorbital nerve is divided into three groups of branches-the palpebral, the nasal and the superior labial. The palpebral branches supply the skin in the lower eyelid. The nasal branches supply the skin of the side of the nose and of the movable part of the nasal septum. The superior labial branches supply the skin of the anterior part of the cheek and the upper lip (2). The infraorbital artery is a branch from the third part of maxillary artery and follows the same course as that of nerve.

Even though the previous literature shows numerous studies on morphometry of IOF, the location of IOF is of great clinical importance as it is located nea $r$ various important anatomical structures such as orbit, nose and oral cavity (3). Since it transmits the important neurovascular structures, the essential knowledge of topographical location of IOF is of utmost important to avoid the injuries to these structures. Infraorbital nerve block is the nerve of choice for surgeries involving orbital, nasal and buccal areas. This nerve can be entered through the intra oral or extra oral route. Hence accurate localizing of the IOF is of great clinical importance as once the location is determined, the needle can be advanced either through the skin 
directly toward the IOF or through the mouth at the level of the incisor at alveolar buccal mucosal margin in the subsulcal plane (4). It provides excellent analgesia for the closure of simple lacerations, biopsies, scar revisions, maxillofacial procedures, as well as various endoscopic and cosmetic cutaneous procedures (5). In case of intractable and pharmacologically unresponsive trigeminal neuralgia, therapeutic infraorbital nerve blocks are commonly done. The presence of accessory IOF may complicate the anesthetization of the region (6). One of the main reason for dentist to avoid infraorbital nerve block is the fear of damage to eyeball which can be avoided by identifying the exact location of IOF in relation to anatomical palpable landmarks (7). Hence the present study was conducted with an aim to find out the incidence of variations in location, shape, dimensions and distance of the IOF from various bony landmarks on both sides of the same skull and the incidence of accessory foramen.

\section{Methods}

The present study was conducted on 90 dry skulls of unknown sex and age, which were obtained from the clinic of anatomy, MVJ Medical college and Research Hospital, Bangalore, Karnataka, and used to study the shape, size, exact position in relation to bony landmarks, presence of accessory IOF. The skulls with damaged infraorbital margin and IOF unilaterally and bilaterally were excluded from the study. All measurements were taken on bilaterally with the help of digital vernier caliper of 0.01 $\mathrm{mm}$ accuracy by two different people.

The following measurements were done in the present study:

1) Shape of IOF,

2) Size of IOF (vertical and horizontal diameters),

3) Location of IOF in relation to maxillary teeth,

4) Presence of accessory IOF,

5) Distance from the center of IOF to infraorbital I margin,

6) Distance from the center of IOF to zygomatico-maxillary suture,

7) Distance from the center of IOF to anterior nasal spine,

8) Distance from the center of IOF to alveolar margin of maxilla along the sagittal plane.

\section{Statistical Analysis}

The data obtained were analysed statistically using SPSS software. Mean and standard deviation were calculated for the distance of IOF from various anatomical landmarks and percentage was calculated for shape, accessory foramen and location of IOF in relation to maxillary tooth. The results were represented in the form of table and graph.

\section{Results}

1) Shape of infraorbital foramen. In the present study including morphometric analysis of IOF, on the right side, oval shape was seen in $51.1 \%$ (46 skulls) and round shape was seen in $48.8 \%$ (44 skulls). On the left side, $55.5 \%$ (50 skulls) had oval shape and $44.4 \%$ (40 skulls) had round shape. Oval shape was predominant in both sides (Figure 1).

2) Size of infraorbital foramen (vertical and horizontal diameters). The vertical diameter of IOF was $3.29 \pm 0.82 \mathrm{~mm}$ on the right side and $3.37 \pm 0.81 \mathrm{~mm}$ on the left side, and horizontal diameter of IOF was $3.77 \pm 0.85 \mathrm{~mm}$ on the right side and $3.90 \pm 0.96 \mathrm{~mm}$ on the left side.

3) Presence of accessory infraorbital foramen. Accessory IOF was present in $7(7.7 \%)$ skulls, in which it was present bilaterally in one skull whereas unilaterally in 6 skulls (2 on right side and 4 on left side) (Figure 2).

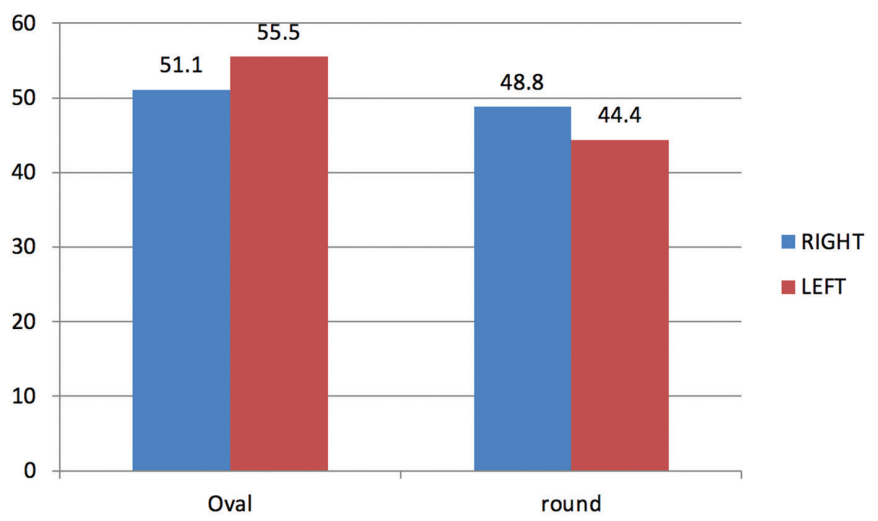

Figure 1. Bar diagram showing the shape of infraorbital foramen on the right and left sides

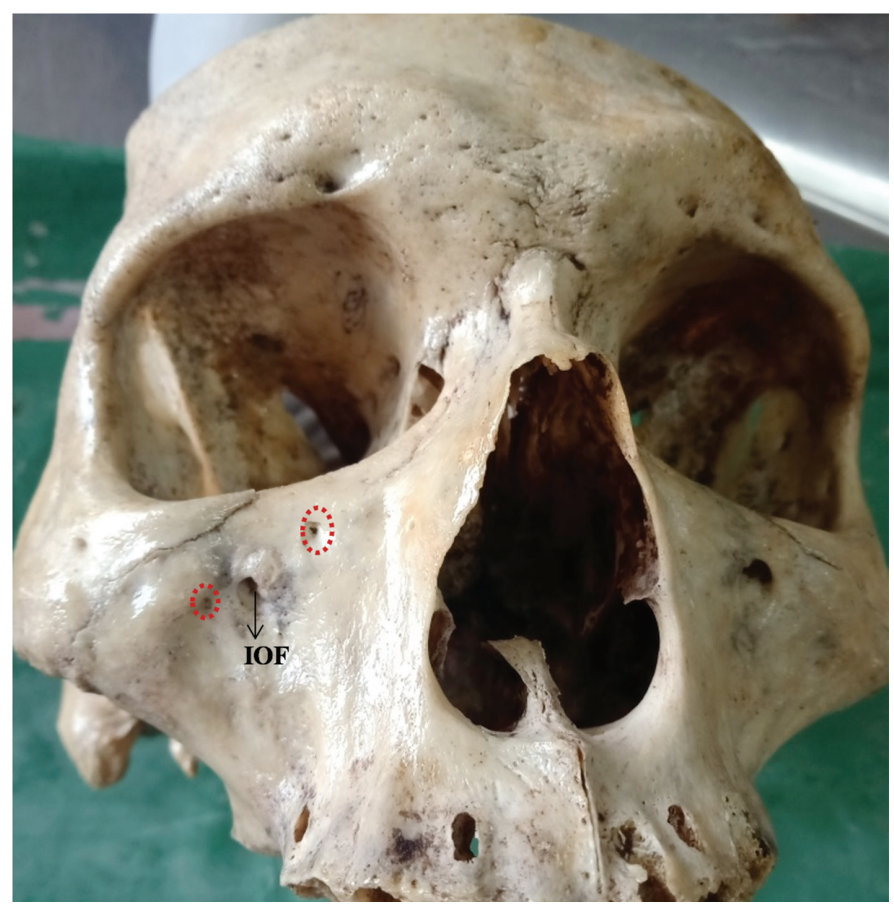

Figure 2. Accessory infraorbital foramen (2 accessory foramina were seen on either side of the normal infraorbital foramen-marked with red circle)

IOF: Infraorbital foramen 
4) Location of infraorbital foramen in relation to maxillary teeth. On the right side, IOF was vertically oriented towards $1^{\text {st }}$ premolar in 27 (30\%) skulls, towards $2^{\text {nd }}$ premolar in 19 (21.1) skulls, located between $1^{\text {st }}$ and $2^{\text {nd }}$ premolar in 14 (15.5\%) skulls, between $2^{\text {nd }}$ premolar and $1^{\text {st }}$ molar tooth in $12(13.3 \%)$ skulls, between canine and $1^{\text {st }}$ premolar in $7(7.7 \%)$ skulls, towards $1^{\text {st }}$ molar in 5 (5.5\%) skulls and towards $2^{\text {nd }}$ molar tooth in 4 (4.4\%) skulls. And, in 2 (2.2\%) skulls, it was vertically directed towards canine tooth.

On the left side, IOF was vertically oriented towards $2^{\text {nd }}$ premolar tooth in $30(33.3 \%)$ skulls, towards $1^{\text {st }}$ premolar in 25 $(27.7 \%)$ skulls, between $1^{\text {st }}$ premolar and $2^{\text {nd }}$ premolar in 12 $(13.3 \%)$ skulls, between $2^{\text {nd }}$ premolar and $1^{\text {st }}$ molar in $10(11.1 \%)$ skulls, located between canine and $1^{\text {st }}$ premolar in $7(7.7 \%)$ skulls, towards $1^{\text {st }}$ molar tooth in $4(4.4 \%)$ skulls, and between $1^{\text {st }}$ molar and $2^{\text {nd }}$ molar in $1(1.1 \%)$ skull. And, in $1(1.1 \%)$ skull, the foramen was vertically directed between incisor and canine.

Hence, on the right side, in majority of skulls, IOFs were vertically oriented towards $1^{\text {st }}$ premolar and on the left side, IOFs were vertically directed towards $2^{\text {nd }}$ premolar tooth.

5) Distance of infraorbital foramen from anatomical landmarks (Table 1, Figure 3).

\section{Discussion}

The recent development in endoscopic surgeries has increased the importance of characteristics of facial foramens. The infraorbital nerve block which is the most common local analgesic technique used for the regional anesthesia of the face. This nerve block has got many advantages as with smaller amount of anesthetic drug, it gives better results than local infiltration. It gives anesthesia without causing any tissue distortion (2). Hence this study is an attempt to analyze the IOF in terms of its shape, size, location, presence of accessory foramens, which provides important data in giving local anesthesia in maxillofacial and plastic surgeries (7).

\begin{tabular}{|c|c|c|c|c|}
\hline \multirow[b]{2}{*}{ Parameters } & \multicolumn{2}{|c|}{ Right side } & \multicolumn{2}{|c|}{ Left side } \\
\hline & $\begin{array}{l}\text { Mean } \\
(\mathrm{mm})\end{array}$ & $\begin{array}{l}\text { Standard } \\
\text { deviation }\end{array}$ & $\begin{array}{l}\text { Mean } \\
(\mathrm{mm})\end{array}$ & $\begin{array}{l}\text { Standard } \\
\text { deviation }\end{array}$ \\
\hline $\begin{array}{l}\text { Infraorbital foramen- } \\
\text { infraorbital margin }\end{array}$ & 6.34 & 1.63 & 6.43 & 1.48 \\
\hline $\begin{array}{l}\text { Infraorbital foramen- } \\
\text { anterior nasal spine }\end{array}$ & 32.21 & 3.07 & 32.26 & 3.29 \\
\hline $\begin{array}{l}\text { Infraorbital foramen- } \\
\text { zygomatico- } \\
\text { maxillary suture }\end{array}$ & 14.11 & 2.24 & 13.87 & 3.59 \\
\hline $\begin{array}{l}\text { Infraorbital foramen- } \\
\text { alveolar margin }\end{array}$ & 27.82 & 4.13 & 28.40 & 3.40 \\
\hline
\end{tabular}

In the present study, oval shape was more predominant on both right and left sides constituting $51.1 \%$ and $55.5 \%$, respectively. Dagistan et al. (8) conducted morphometric analysis of IOF with cone computed tomography. In their study, $58 \%$ skulls showed oval shape and $42 \%$ had round shape. Singh (9) conducted a study on 110 skulls, showed $71 \%$ oval shape and $29 \%$ circular shape. Majority of studies showed oval shape as the most predominant type, followed by round shape. Some of the studies reported semilunar and triangular shapes, which was not present in our study.

The vertical diameter of IOF was $3.28 \pm 0.82 \mathrm{~mm}$ on the right side and $3.36 \pm 0.81$ on the left side. The horizontal diameter was $3.76 \pm 0.85 \mathrm{~mm}$ on the right side and $3.90 \pm 0.96 \mathrm{~mm}$ on the left side. In a study by Singh (9), the mean vertical dimensions on the right and left sides were $3.39 \mathrm{~mm}$ and $3.75 \mathrm{~mm}$, respectively. The mean horizontal dimensions on the two sides were $3.19 \mathrm{~mm}$ and $3.52 \mathrm{~mm}$. The diameter of the IOF is related proportionately to that of thickness of infraorbital nerve and vessels (10).

The distances between IOF and various novel anatomical landmarks were chosen as these reference points are easily identifiable even in the presence of pathological lesions of maxillofacial regions such as fracture or edema (5). In the present study, the distance between IOF and infraorbital margin was $6.34 \pm 1.63 \mathrm{~mm}$ on the right side and $6.4 \pm 1.48 \mathrm{~mm}$ on the

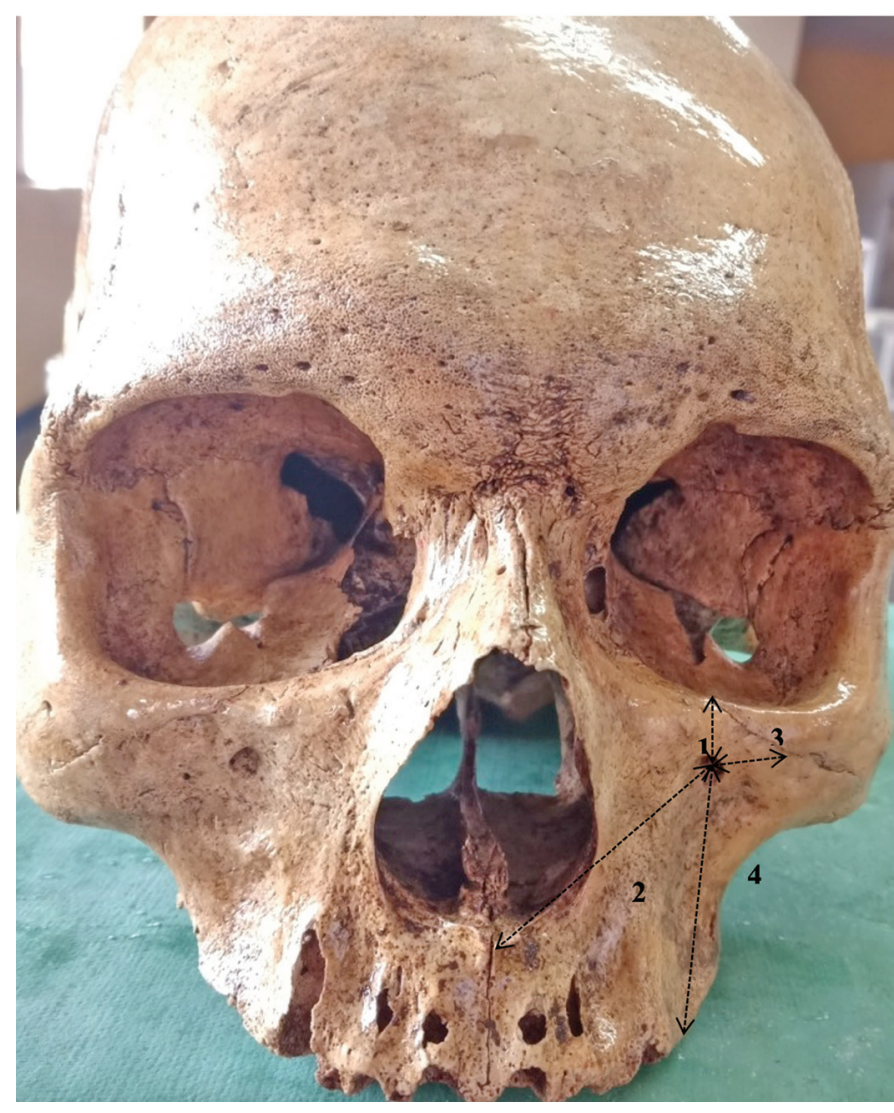

Figure 3. Distance from the center of infraorbital foramen to infraorbital margin (1), anterior nasal spine (2), zygomatico-maxillary suture (3) and alveolar margin (4) 
left side. This finding of our study closely relates with that of the study by Oliveira et al. (11) (right: $6.49 \pm 1.68 \mathrm{~mm}$, left: $6.52 \pm 1.82$ $\mathrm{mm}$ ), Singh (9) (right: $6.12 \mathrm{~mm}$ and left: $6.19 \mathrm{~mm}$ ), and Lokanayaki (12) $(6.33 \pm 1.48 \mathrm{~mm})$. Since the infraorbital margin is very prominent and easy to locate, it can be used as reference point by dentist while performing the nerve block anesthesia. The major limitation for dentists while taking infraorbital margin as landmark is the fear of damage to patient's eye (13).

The distance between IOF and lower end of alveolar margin of maxilla was $27.82 \pm 4.13 \mathrm{~mm}$ on the right side and $28.40 \pm 3.40$ $\mathrm{mm}$ on the left side. Tewari et al. (14) conducted a study on 60 skulls of South Indian population and observed that the distance was $27.88 \pm 4.25 \mathrm{~mm}$ on the right side and $27.31 \pm 4.5 \mathrm{~mm}$ on the left side, which closely correlates with our study. Bharthi and Puranik (15) done a morphometric analysis of IOF in 100 dry skulls and the mean vertical distance from lower margin of IOF to upper alveolar margin was $28.93 \pm 4.11 \mathrm{~mm}$ on the right side and was $28.42 \mathrm{~mm} \pm 4.43 \mathrm{~mm}^{2}$ on the left side. Although it is easier to locate alveolar margin of maxilla, one of the main drawbacks in this measurement, it may resorb as a result of aging or following tooth extraction or due to any periodontal disease.

Another parameter which helps to locate the IOF is the distance between the foramen and zygomatico-maxillary suture, which was $14.11 \pm 2.23$ on the right side and $13.87 \pm 3.59 \mathrm{~mm}$ on the left side. Raj et al. (16) conducted a study on 70 dry skulls and observed that the distance between them was $14.71 \pm 2.54$ $\mathrm{mm}$ on the right side and was $14.83 \pm 2.36 \mathrm{~mm}$ on the left side. In our study, the distance between the IOF and anterior nasal spine was $32.21 \pm 3.07 \mathrm{~mm}$ on the right side and $32.26 \pm 2.29 \mathrm{~mm}$ on the left side. Nanayakkara et al. (4) conducted a study on 54 skulls of Sri Lankan skulls and the distance was $33.81 \pm 2.68 \mathrm{~mm}$ on the right side and $34.23 \pm 2.56 \mathrm{~mm}$ on the left side. In a study by Veeramuthu et al. (17) on 105 adult dry skulls, the same distance was $32.62 \pm 3.4 \mathrm{~mm}$ on the right side and $33.52 \pm 3.37$ $\mathrm{mm}$ on the left side. Studies by Lopes et al. (18) and Agthong et al. (19) showed that the distance between anterior nasal spine and IOF was higher than our values, which suggests that the data from one population cannot be exchanged with other population as all these values are population specific.

In the present study, the most common location of IOF in relation to maxillary teeth was $1^{\text {st }}$ premolar tooth on the right side and $2^{\text {nd }}$ premolartooth on the left side. Varshney and Sharma (20) observed that the most common location was in line with the $2^{\text {nd }}$ premolar tooth followed by its position between first and second premolar teeth. In a study by Aziz et al. (21), the most common location of the IOF in white, black and Hispanic skulls was in line with first premolar tooth. Varshney and Sharma (20) found that the majority of IOFs were oriented to second premolar tooth on the right side and between second premolar and first molar teeth on the left side. The literature shows extensive variations in the location of IOF in relation to maxillary teeth, which may complicate the effectiveness of nerve block during regional anesthesia (14).

Multiple IOF is the most common occurrence and the most common cause for the failure during infiltrative anesthesia for maxillofacial surgeries. The common cause for the appearance of accessory foramen is due to the branching of nerves during development. In the present study, the accessory foramen was seen in $7.7 \%$ of skulls. Berry (22) reported the frequency of occurrence of accessory foramen in different races and showed the rates as $6.7 \%$ in Indians (Punjabi), 6\% in North Americans and $7.5 \%$ in Burmese. Identification of multiple such foramen is important while administering the drugs because in the presence of accessory foramen, the amount of drug may become inadequate and will not serve the purpose (18).

The main limitation of the present study is its small sample size; in the current study, we have used only 90 skulls due to the limited availability of bones, and age and sex of bones were unknown. The present study was performed in a particular center not involving multiple regions. Due to these limitations, we could not find out variations in the foramen in terms of age, sex or racial difference.

\section{Conclusion}

IOF transmits infraorbital nerve commonly used for regional anesthesia technique in nasal, oral and dental surgeries as it yields good intraoperative and postoperative results. In the present study, oval shape of foramen was more common followed by round shape. Semilunar and irregular shapes were not seen in current study. Knowledge of location of IOF is important because injuries to infraorbital nerve and vessels may occur in numerous surgical procedures of maxillofacial region. Hence this foramen should be approached carefully to avoid damage.

\section{Ethics}

Ethics Committee Approval: Since this is an osteological study which is not involving any living subject and the identity of an individual is not revealed, ethical clearance is exempted from our Institutional ethical committee.

Informed Consent: It's not necessary.

Peer-review: Externally and internally peer-reviewed.

\section{Authorship Contributions}

Concept: V.KL., Design: V.KL., Data Collection or Processing: V.KL., J.N.N., Analysis or Interpretation: V.KL., Literature Search: J.N.N., Writing: V.KL., J.N.N.

Conflict of Interest: No conflict of interest was declared by the authors.

Financial Disclosure: The authors declared that this study received no financial support. 


\section{References}

1. AK Datta. Essentials of human anatomy. Head and neck. 5th edition. Kolkata: Current Boks International. p:151.2009.

2. Kulkarni NV. Clinical Anatomy (A problem solving approach). 2nd edition. New Delhi. Jaypee Publication. 2012;326.

3. Bösenberg AT, Kimble FW. Infraorbital nerve block in neonates for cleft lip repair: anatomical study and clinical application. Br J Anaesth. 1995;74:506-508.

4. Nanayakkara D, Peiris R, Mannapperuma N, Vadysinghe A. Morphometric Analysis of the Infraorbital Foramen: The Clinical Relevance. Anat Res Int. 2016;2016:7917343.

5. Przygocka A, Podgórski M, Jędrzejewski K, Topol M, Polguj $M$. The location of the infraorbital foramen in human skulls, to be used as new anthropometric landmarks as a useful method for maxillofacial surgery. Folia Morphol (Warsz) 2012;71:198-204.

6. Karpagam NG, Thenmozhi MS. A study of morphometric analysis of infraorbital foramen in South Indian dry skulls. Int J Pharm Sci Res. 2016;8:1318-1319.

7. Srinisha M, Babu KY, Mohanraj KG. Anthropometric measurement and variations in positions of infraorbital foramen and its surgical importance. Drug Invent Today. 2018; 10:2462-2464.

8. Dagistan S, Miloğlu Ö, Altun O, Umar EK. Retrospective morphometric analysis of the infraorbital foramen with cone beam computed tomography. Niger J Clin Pract. 2017;20:1053-1064.

9. Singh R. Morphometric analysis of infraorbital foramen in Indian dry skulls. Anat Cell Biol. 2011;44:79-83.

10. Boopathi S, Chakravarthy Marx S, Dhalapathy SL, Anupa $S$. Anthropometric analysis of the infraorbital foramen in a South Indian population. Singapore Med J. 2010;51:730735.

11. Oliveira J, De EM, Moreira RT, Neto BL, Silva CMF da,Lima FJC. A Morphological and Biometric Study of the Infraorbital Foramen (E2 - Sibai Point) in Adult Skulls. Int J Morphol. 2012;30:986-992.
12. Lokanayaki V. Anatomic variations of infraorbital foramen. CIBTech Journal of Surgery. 2013;2:30-36.

13. Masabni O, Ahmad M. Infraorbital Foramen and Pterygopalatine Fossa Location in Dry Skulls: Anatomical Guidelines for Local Anesthesia. Anat Res Int. 2017;2017:1403120.

14. Tewari S, Gupta C, Palimar V, Kathur SG. Morphometric analysis of infraorbital foramen in South Indian skull. Bangladesh J Med Sci. 2018;17:562-566.

15. Bharthi DA, Puranik DM. Morphometic study of infraorbital foramen in dry human skulls. NJIRM. 2013;4:42-48.

16. Raj T, Mishra A, Mishra P. Morphometheric analysis of infraorbital foramen in North Indian skulls. Indian J Basic Appl Med Res. 2014;4:185-192.

17. Veeramuthu $M$, Varman $R$, Shalini, Manoranjitham. Morphometric analysis of infraorbital foramen and incidence of accessory foramen and its clinical implications in dry adult human skull. International Journal of Anatomy and Research. 2016;4:2992-3000.

18. Lopes P, Pereira G, Santos A, Freitas C, Abreu B, Malafaia A. Morphometric analysis of the infraorbital foramen related to gender and laterality in dry skulls of adult individuals in southern Brazil. Braz J Morphol Sci. 2009;26:19-22.

19. Agthong S, Huanmanop T, Chentanez V. Anatomical variations of the supraorbital, infraorbital, and mental foramina related to gender and side. J Oral Maxillofac Surg. 2005;63:800-804.

20. Varshney R, Sharma N. Infraorbital foramen-Morphometric study and Clinical application in adult Indian skulls. Saudi J Health Sci. 2013;2:151-155.

21. Aziz SR, Marchena JM, Puran A. Anatomic characteristics of the infraorbital foramen: a cadaver study. J Oral Maxillofac Surg. 2000;58:992-996.

22. Berry AC. Factors affecting the incidence of non-metrical skeletal variants. J Anat. 1975;120:519-535. 